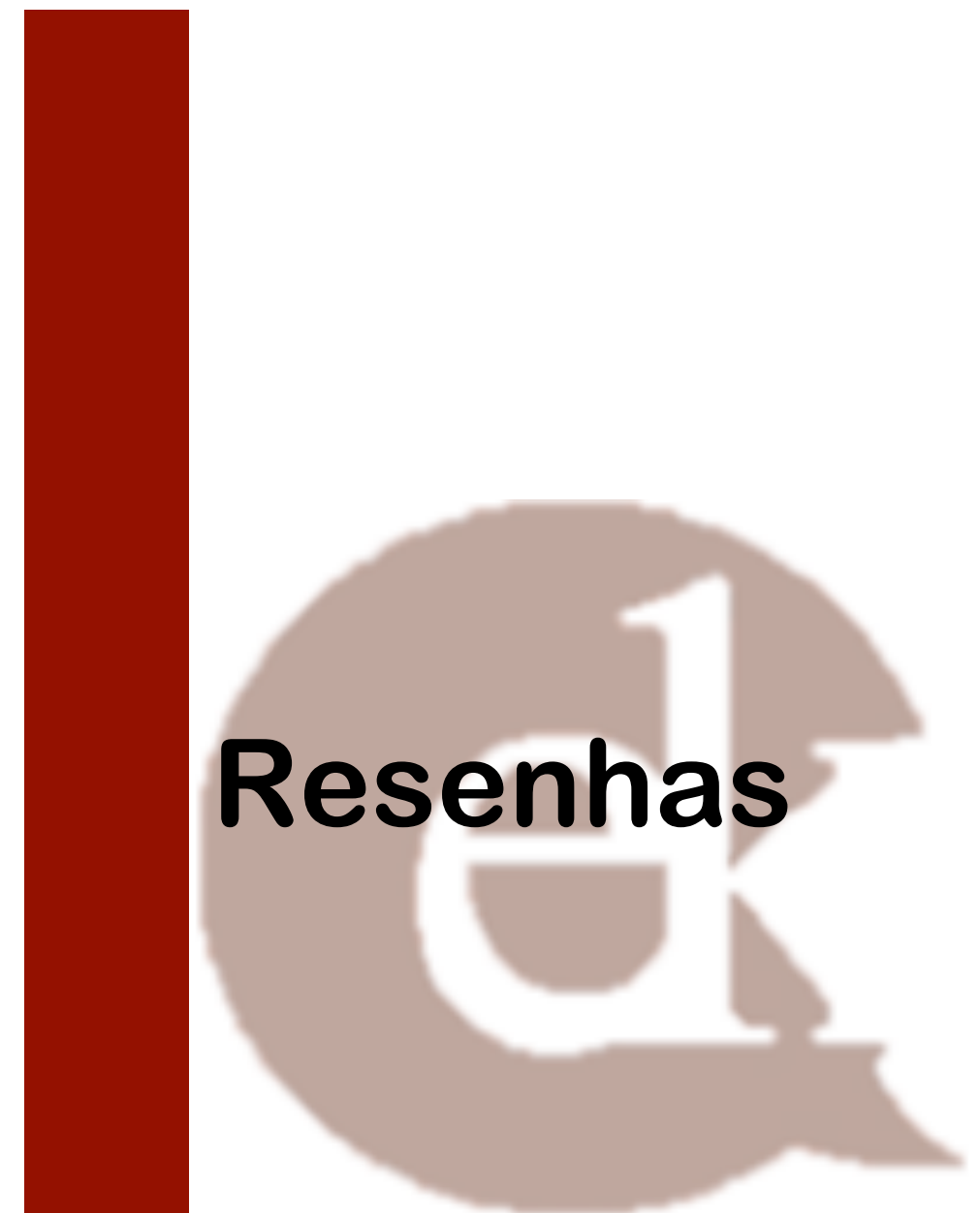




\title{
Resenha de "Heidegger/Wittgenstein: Confrontos"
}

DOI: 10.12957/ek.2021.54974

\author{
Thiago André Moura de Aquino ${ }^{1}$ \\ Universidade Federal de Pernambuco \\ tama_aquino@hotmail.com \\ https://orcid.org/0000-0003-1523-147X
}

\section{Resenha crítica e bibliográfica de:}

Giannotti, José Arthur. Heidegger/Wittgenstein: Confrontos. São Paulo: Companhia das Letras, 2020. 477 páginas.

O título do mais recente livro de José Arthur Giannotti anuncia uma disputa filosófica. É inegável a tensão proveniente das marcantes diferenças de posição, método e projeto filosófico entre Heidegger e Wittgenstein. Não foi incomum caracterizarem a fenomenologia e a filosofia analítica como caminhos divergentes, quiçá incompatíveis do fazer filosófico. A incompatibilidade, neste caso, significaria total impossibilidade de diálogo produtivo. Teríamos uma posição extrema com consequências bastante questionáveis; pois de fato, se pressupomos que a diferença de perspectiva é realmente radical até o limite da incompatibilidade, então, somente restaria optar entre a refutação unilateral do interlocutor ou a "elegante" ignorância recíproca. Por certo, não parece correto afastar tais recusas iniciais de diálogo como simples manifestação de fechamento doutrinal ou mero equívoco; podemos reconhecer que alguns obstáculos e impedimentos foram e são efetivos. Este reconhecimento é importante, porque torna o seu enfrentamento meritório. E também porque torna compreensível que um diálogo produtivo não necessariamente conduz seja à uma síntese superior, seja à superação de uma das

\footnotetext{
${ }^{1}$ Doutor em Filosofia pela Ludwig-Maximilians-Universität München. Atua como professor adjunto no departamento de Filosofia da Universidade Federal de Pernambuco.
} 
posições. Nesta direção, são muito bem vindas, no trabalho de mediação entre fenomenologia e filosofia analítica, todas as contribuições que indiquem maneiras instigantes de trânsito entre os polos da relação, promovendo aproximações e resguardando as diferenças a partir de problemas fundamentais.

Com sua contribuição à construção do debate possível entre Heidegger e Wittgenstein, Giannotti dá continuidade ao esforço iniciado há algumas décadas. Logo no início da obra, o autor reconhece que "a bibliografia é enorme e só pode ser atravessada de viés" (GIANNOTTI, 2020, p. 17). Cita o livro de Stephen Muhall, On Being in the World: Wittgenstein and Heidegger on Seeing Aspects (1990), como referência de um estudo próximo às suas intenções. Abrangendo um espectro maior, poderíamos mencionar outras publicações importantes tais como, por exemplo, o artigo pioneiro de Karl-Otto Apel no primeiro volume de Transformações da Filosofia (1973). Além de artigos de Richard Rorty, Charles Taylor, David Stern, para citar apenas alguns nomes mais conhecidos. No Brasil, temos importantes estudos publicados por Zeljko Loparic, Luiz Hebeche, dentre outros. Não resta dúvida que ainda há muito o que investigar acerca desta relação, trata-se de uma área de pesquisa que permite ainda desenvolvimentos e merece prosseguimento. A publicação do livro de José Arthur Giannotti reforça esta afirmação, evidenciando a relevância da elaboração deste diálogo, no qual se decide também, sob muitos aspectos, o que pode ser denominado de contemporaneidade filosófica em suas limitações e possibilidades vindouras.

O livro Heidegger/Wittgenstein: confrontos pode ser dividido em duas partes principais dedicadas a cada um dos pensadores escolhidos. É o próprio autor que nos chama a atenção para "um desequilíbrio nos espaços dedicados a Heidegger e a Wittgenstein" (GIANNOTTI, 2020, p.17). A primeira parte do estudo está exposta nos cinco capítulos iniciais dedicados a Heidegger; a segunda parte, dedicada a Wittgenstein, é composta pelos três últimos capítulos. A justificação desta desproporção é dada com a seguinte observação: “A despeito de este livro ter pretensões didáticas, todo ele está armado para defender a tese da crise da razão. Para isso precisei pontuar os passos decisivos do percurso de Heidegger. No caso de Wittgenstein, essa crise se configura basicamente nos últimos escritos sobre as gramáticas dos verbos psicológicos. Daí o encurtamento da narração. Além do mais, sobre Wittgenstein já tenho outros livros publicados." (GIANNOTTI, 2020, p. 17) De fato, além de ter feito a primeira tradução, 
acompanhada de introdução, do Tractatus Logico-Philosophicus para o português, Giannotti publicou também um extenso estudo intitulado Apresentação do mundo considerações sobre o pensamento de Ludwig Wittgenstein. A justificação para a divisão desigual do livro não se esclarece, todavia, somente com a indicação de informações bibliográficas externas à obra, transparece mais claramente na organização do texto em função da problematização implícita do conceito de racionalidade. Na prática, a "tese da crise da razão" não é discutida diretamente no texto, transparecendo nas entrelinhas e cruzamentos da exposição, operando como referência principal da convergência entre os autores estudados. As duas obras, promovem a partir de questões, métodos e projetos distintos, o mesmo "velório da lógica formal como reguladora das questões lógicometafísicas" (GIANNOTTI, 2020, p.17).

A primeira parte do texto, como vimos, se propõe a "pontuar os passos decisivos do percurso de Heidegger" (GIANNOTTI, 2020, p.17) desde as primeiras formulações prévias a Ser e Tempo até as últimas meditações acerca da técnica e o destino do ocidente. No primeiro capítulo, Sentido e Ser, é discutida a crítica da proposição a partir do seu enraizamento no mundo, enquanto estrutura total de significância. Ao invés de estabelecer autonomamente a sua relação com estados-de-coisas, determináveis através de predicados, a proposição depende da significação do mundo circundante no qual o seraí se movimenta na cotidianidade. A pré-compreensão antepredicativa que libera instrumentos para a conjuntação [Bewandtnis], na lida da ocupação, já articula significação através do como-hermenêutico. A desmontagem da proposição apofântica consiste, justamente, na explicitação de sua dependência à uma operação hermenêutica que é anterior as "relações linguísticas da expressão" (GIANNOTTI, 2020, p.59.) Já se anuncia aqui a temática da aletheia, que abala a centralidade da lógica e o pressuposto de que a proposição seja o lugar da verdade. A função elementar da linguagem se evidencia mais propriamente "circunscrevendo nela o papel original da verdade como procedimento de apresentar algo" (GIANNOTTI, 2020, p.57), papel este que é primário frente a determinação de um sujeito lógico por um predicado universal numa proposição apofântica. Em síntese, importa demonstrar fenomenologicamente que "antes da proposição propriamente asseverativa e articulada, antes, portanto, dos liames gramaticais e linguísticos do discurso sobre o entificado, operam comportamentos significantes de descobrir e de encobrir ligados à apresentação do próprio ser de algo que no mundo se 
mostra para o ser-aí falante." (GIANNOTTI, 2020, p. 64) Trata-se da conhecida tese da “proposição enquanto modo derivado da interpretação", exposta no § 33 de Ser e Tempo; discutida neste primeiro capítulo, fundamentalmente, através da preleção Lógica $-A$ pergunta pela verdade (1925/26). Giannotti opta por analisar este curso, porque quer discutir e destacar aspectos centrais do debate travado com o Husserl das Investigações Lógicas. São estas as elaborações do pensamento de Heidegger que antecedem e preparam Ser e Tempo, que o autor elege como ponto de partida da interpretação do percurso do pensador alemão.

O segundo capítulo, Do compreender ao discurso, avança na discussão da experiência da significação do mundo circundante antepredicativo, procurando, nas palavras do autor, "resumir como esse mundo silencioso hermenêutico se articula em Ser e Tempo." (GIANNOTTI, 2020, p.15) Nas primeiras três seções são apresentados os momentos da abertura do ser-aí, discutidas no capítulo cinco da primeira seção de Ser e Tempo: Befindlichkeit (I), compreensão (II), interpretação, proposição e discurso (III). As duas últimas seções, IV e V - mais curtas - introduzem o tema da temporalidade em conexão com os temas da finitude, responsabilidade e historicidade. O terceiro capítulo, Um caminho intermediário propõe, numa abordagem inspirada nas descrições da trajetória do Wittgenstein, elaborar "a mediação entre Ser e Tempo e as obras posteriores" (GIANNOTTI, 2020, p. 15). Em outras palavras, procura encontrar uma espécie de "período intermediário" no pensamento do Heidegger da década de 30. Giannotti examina aqui a preleção Lógica e a pergunta pela essência da linguagem, ministrada em 1934, guiado pelo pressuposto de que a virada (Kehre) é consequência da descoberta "das dificuldades de, partindo da constituição da trama do ser-aí vindo a ser próprio, chegar até as conformações historializantes singulares do próprio ser determinando-se por si mesmo mediante o tempo; não como um passar, mas se desenhando em épocas." (GIANNOTTI, 2020, p.135). Sem adentrar numa discussão detalhada, que fugiria da delimitação escolhida para o capítulo, Giannotti apresenta também neste capítulo, algumas observações acerca da política em Heidegger na seção IV. Defendendo que a raiz filosófica do "engajamento profundamente conservador e expressamente antidemocrático"(p. 138), do pensador alemão no movimento nazista, deve ser encontrada na difícil problemática da relação entre história e decisão. 
O quarto capítulo, A Caminho do seer, apresenta a outra versão que a questão do ser recebeu com a tematização da historicidade do ser. O impasse de Ser e Tempo, qual seja, a dificuldade de encontrar uma passagem do tempo do ser-aí para o próprio ser, seria enfrentado por Heidegger com a consideração do "tempo histórico atravessando o próprio ser.” (GIANNOTTI, 2020, p. 185) A crítica da metafísica se concretiza numa transformação do próprio pensamento, cujo gesto fundamental se torna um consentimento à "essenciação" [Wesung] do ser em suas doações epocais. Exercido enquanto meditação em trânsito entre o início grego - rememorado no Andenken da história do ser em suas doações e desvios - e a preparação de um outro início, o pensamento reconhece que "há um momento em que é preciso dar um salto para acolher o próprio ser como acontecimento (Ereignis), no dar-se (es gibt) que vem a ser igualmente um a-propriar-se (Er-eignis) do dar e daquele que o recebe." (GIANNOTTI, 2020, p. 204) Este consentimento (Zusage) que acolhe o ser, que o recebe, é parte integral do pertencimento do ser-aí ao ser; permitindo uma correspondência à essência da técnica coerente com a ambivalência que entrelaça, no instante histórico, perigo e salvação. Giannotti observa que "na virada se torna claro que na conexão entre ser e homem o privilégio provém do ser" (GIANNOTTI, 2020, p. 194), por isso, importa redimensionar o papel e o significado do ser-aí, ele se torna, então, o "ser do aí da abertura veladora exercida pelo mortal enquadrado no Ereignis." (GIANNOTTI, 2020, p.238) Neste denso capítulo, o tema da linguagem é pouco discutido, com a única ressalva da breve seção IV que versa sobre aspectos do trabalho etimológico de Heidegger e sua relevância filosófica.

$\mathrm{O}$ tema reaparece no capítulo quinto, A linguagem apropriadora. $\mathrm{O}$ "nervo da questão", desenvolvida nele se determina através da reconsideração do "essenciar" da linguagem a partir clareira do ser. Se a linguagem pertence à aletheia, na ambivalência do desvelamento/velamento, pergunta-se: "nessas condições, como a linguagem se articula desvendando-se e ocultando-se?" (GIANNOTTI, 2020, p.251) O Ereignis, que carece do ser-aí para a guarda da verdade do ser, se apropria do humano através da linguagem. Na descrição de Giannotti: “Cumpre notar desde já que a linguagem se apropria de cada mortal para que cada um a escute conforme participe da quaternidade anunciada pelo Ereignis no jogo de espelho do Zuruf e do Anruf, do aceno e do chamamento, da virada e da contravirada.” (GIANNOTTI, 2020, p.261) A posse do humano pela linguagem é uma convocação para o exercício da palavra no seu poder de 
nomeação fundamental, na sua capacidade de chamar o nomeado ao desvelamento do seu ser no próprio dizer. Trata-se de encontrar caminhos para uma experiência da linguagem que não a restrinja a um sistema de sinais empregado para significar entidades e que permita também que o seer venha à palavra. Isto torna o diálogo com o poetar extremamente profícuo, na medida em que a palavra se apresenta aqui da fundação de mundos históricos, abrindo a possibilidade da habitação poética. Pensamento e poesia se comunicam enquanto modos diferentes e próximos da linguagem apropriadora.

A segunda parte do livro, composta pelos três últimos capítulos, é dedicada a Wittgenstein. O sexto capítulo, Passando pelo Tractatus, já anuncia no título que não irá apresentar uma "análise minuciosa." (GIANNOTTI, 2020, p. 287). Para demarcar os limites da apresentação, o autor seleciona para discussão unicamente temas relevantes ao questionamento do ser feito na obra madura do pensador austríaco. Em especial, Giannotti chama atenção, logo no início do capítulo, para o fato de que "ao distinguir o como e o que de toda linguagem (...) já é possível inaugurar uma conversa entre Heidegger e Wittgenstein” (GIANNOTTI, 2020, p. 287) Ele refere se à ao aforismo TLP 5.552: “a lógica é anterior a toda experiência - de que algo é assim. Ela é anterior ao como, não é anterior ao quê". O entendimento da lógica pressupõe a experiência de "que algo é”, ou seja, da totalidade do mundo. No decorrer do capítulo, acompanhamos uma exposição sintética e precisa dos momentos fundamentais da "teoria" da significação linguística enquanto afiguração de estado de coisas possíveis; compreendendo que “(...) uma proposição somente pode afigurar uma situação na medida em que vem a ser articulada por um método de projeção que mostre que seus elementos estabelecem uma relação com os elementos do estado de coisa enunciado. O método de projeção transforma os sinais em símbolos na medida em que articula imagem e real, impondo uma lógica aos dois lados inicialmente desconectados." (GIANNOTTI, 2020, p. 294.) É na última seção do capítulo (IV), que a distinção entre espelhamento/afiguração recebe uma interpretação à luz da relação entre o mundo enquanto totalidade lógica (articulação prévia de possibilidades combinatórias) e o singular dado nas concatenações de objetos em estados de coisas. O conceito formal de totalidade - criticado por Heidegger como fantasmagórico pela restrição ao que é determinável na efetividade factual (GIANNOTTI, 2020, p.309) opera na arquitetônica do Tractatus tanto na lógica da linguagem enquanto "ordem a 
priori" acerca do quê anterior a toda experiência do como (do ser-assim). (T. 5552), quanto no núcleo das experiências mística, ética e estética.

O sétimo capítulo, Lógica das Vivências, aborda a análise gramatical dos verbos psicológicos. Especial destaque recebe na discussão a noção de exteriorização ( Äusserung), interpretada por Giannotti no entrelaçamento entre comportamentos, expressões linguísticas e falantes na situação prática. No seu cerne, a argumentação procura defender que a impossibilidade da linguagem privada (a exigência de critérios públicos para o emprego de termos psicológicos) não implica que não exista nenhum tipo de relação entre uso da linguagem e vivência. Obviamente, isto não significa que se almeja construir a gramática das palavras mentais de acordo com o "modelo de objeto e designação", senão reconhecer "na linguagem um movimento de interiorização/exteriorização que questiona o papel tradicional da alma na transformação de sinais em signos. Esta se despoja de qualquer conteúdo e se resume a uma regulação gramatical." (GIANNOTTI, 2020, p.16) Há, por exemplo, um “momento pessoal" (GIANNOTTI, 2020, p. 378) ineliminável nas exteriorizações, pois “operando no cruzamento do interior e do exterior, a exteriorização se situa no relacionamento entre pessoas, mas podendo se enviesar para o lado do próprio falante" (GIANNOTTI, 2020, p. 378) Para Giannotti, a vivência do falante é relevante nas exteriorizações. Se não desempenha o papel de um referente interior, importa no contexto dos jogos de linguagem que são sempre exercidos na ambiência das formas de vida. Se for verdade que as palavras ganham significado no fluxo da vida, isto vale também para as palavras do vocabulário psicológico. No cotidiano, um falante, imerso nas circunstâncias de ação pode, em comunicação com outros, exteriorizar seu "ânimo". Afinal, "se a linguagem está sempre procurando critérios exteriores para se completar, nem por isso as palavras não precisam ser vividas." (GIANNOTTI, 2020, p. 373) No sétimo capítulo, A indeterminação lógica do outro, prossegue a análise da distinção gramatical entre interior/exterior "comparando os jogos de linguagem nos quais as palavras 'interior' e 'exterior' comparecem, evidenciando-se o conceito não só pelo que ele determina, mas também pela indeterminação que cerca tais jogos." (GIANNOTTI, 2020, p. 429-30) O conceito de variação de aspecto, elaborado na descrição da gramática do "ver como", possibilita discutir a vivência tipicamente linguística do significado. Nas palavras do autor, "sem o aprendizado pessoal de ver isto como aquilo, sem essa técnica individualizada, cada 
pessoa não pode falar vivenciando o significado do que diz. Por isso até mesmo a nomeação, que por muito tempo foi tomada como ato original da linguagem, não pode funcionar sem a ambiência atuante e vivida do falante particular, a qual, em última instância, remete a uma forma de vida." (GIANNOTTI, 2020, p.422-23).

A última parte do livro, Alinhavando Questões, não é propriamente uma conclusão da discussão. Parte do texto, aliás, já havia sido publicada anteriormente para permitir um vislumbre da direção e conteúdo da confrontação desenvolvida pela investigação. De fato, o final do texto apresenta a relação Heidegger e Wittgenstein a partir de dois temaschaves, a crise da razão e a pergunta pelo sentido do mundo, alinhavados (para utilizar uma palavra cara ao autor) pela análise da crise da modernidade. A civilização técnicoindustrial é considerada, pelos dois pensadores, indício da decadência do ocidente, ecoando implicitamente o diagnóstico de Spengler, ainda que os critérios do diagnóstico sejam outros. Diante do desafio da modernização inacabada, somos convidados por Heidegger e Wittgenstein a rever a estrutura e função do logos, uma revisão que abala as pretensões da racionalidade metafísica pela demonstração de que a significação linguística participa do acontecer histórico dos destinamentos do seer ou da pluralidade dos jogos de linguagem. A razão entra em crise pela rejeição de um fundamento último que pudesse ser independente da historicidade e da linguagem. No mesmo modo o sentido do mundo se reformula também, assumindo a variação e multiplicidade como momentos insuperáveis. Afinal, “(...) como mostraram Heidegger e Wittgenstein, não há uma razão - uma faculdade de alinhavar argumentos numa única cadeia dedutiva -, somos obrigados a lidar com as diferenças a partir delas mesmas.” (GIANNOTTI, 2020, p.461)

Este livro, Heidegger/Wittgenstein: Confrontos enriquece o debate filosófico no Brasil acerca das relações entre fenomenologia e filosofia analítica. O texto impressiona pela capacidade que demonstra em aliar a abrangência da pesquisa ao percorrer os momentos fundamentais do percurso de cada autor (nisto talvez consistam suas "pretensões didáticas" comentadas pelo autor no prefácio), com a minúcia da análise mais detida dos textos, em especial os aspectos relevantes para a discussão da crise da racionalidade. Da centralidade concedida à problemática da racionalidade decorre um aspecto inovador da obra, qual seja, a ênfase concedida aos últimos escritos dos pensadores estudados. Ao invés, de construir o diálogo fundamentando a discussão na relação possível entre Ser e Tempo e as Investigações Filosóficas, o que é o mais usual, 
Giannotti destaca a importância da elaboração do pensamento do acontecimentoapropriativo e da obra Sobre a Certeza para o diálogo entre Heidegger e Wittgenstein. Apesar do título do livro, entretanto, não encontramos nas suas páginas uma confrontação efetiva dos dois filósofos, cujos percursos são apresentados de maneira independente, em paralelo. As análises cuidadosas de cada trajetória particular apontam para uma convergência fundamental, qual seja, a libertação do "imperialismo da lógica formal como única lógica da verdade" (GIANNOTTI, 2020, p.437), sem colocar em discussão direta e frontalmente as diferenças de pressupostos, método e projeto que desembocam nesse resultado comum. As tensões e divergências mencionadas, porém não são trabalhadas através de um embate crítico mais desenvolvido. A despeito deste fato, pelas qualidades acima ressaltadas, José Arthur Giannotti apresenta com esta publicação uma contribuição muito bem vinda à discussão do fenômeno da linguagem no contexto filosófico brasileiro. Heidegger, Wittgenstein: com seus percursos "deixaram diante de nós caminhos abertos nunca antes entrevistos." (GIANNOTTI, 2020, p.449) Caminhos, sem dúvida, que transitaremos com uma clareza um pouco maior com base nas instigantes sinalizações hermenêuticas apresentadas nesta obra.

\section{Referências bibliográficas}

APEL, K.-O. Wittgenstein und Heidegger: Die Frage nach dem Sinn von Sein und der Sinnlosigkeitsverdacht gegen alle Metaphysik, in: Transformation der Philosophie I: Sprachanalytik, Semiotik, Hermeneutik. Frankfurt am Main: Editora Suhrkamp: 1973. . Transformação da Filosofia, Vol. I. São Paulo: Editora Loyola : 2000.

GIANNOTTI, J., Apresentação do Mundo - Considerações sobre o Pensamento de Ludwig Wittgenstein, São Paulo, Companhia das Letras, 1995. . Heidegger/Wittgenstein : Confrontos. São Paulo : Companhia das Letras, 2020.

HEBECHE, L. Heidegger e os indícios formais. Veritas, PUC- Porto Alegre, v. 46, n. 184, p. 571-592, 2001.

LOPARIC, Z. Sobre Ética em Heidegger e Wittgenstein. In: Natureza Humana 2. São Paulo : Educ, jun. n.1, p. 129-144, 2000. 
MUHALL, S. On Being in the World: Wittgenstein and Heidegger on Seeing Aspects, London: Routledge: 1990.

. Inheritance and Originality, Wittgenstein, Heidegger, Kierkegaard. Nova Iorque: Oxford university Press: 2001.

RORTY, Richard, Wittgenstein, Heidegger, and the Reification of language, in: The Cambridge Companion to Heidegger, Cambridge University Press, 1993, p.337-357.

STERN, D. Heidegger and Wittgenstein on the Subject of Kantian Philosophy, in: David E. Klemm/Günter Zöller (Hg.), Figuring the Self: Subject, Absolute, and Others in Classical German Philosophy, Albany, p. 245-260, 1997.

Recebido em: 01/10/2020 | Aprovado em: 14/11/2020

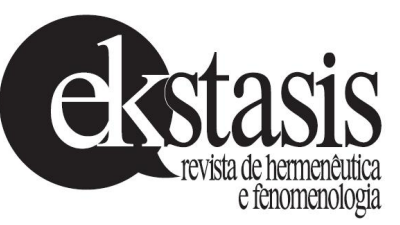

